\title{
Immigration
}

through the lens

of nationals

and immigrants:

self-interest, solidarity,

autochthony and

moral determinants

Alice Ramos 


\section{A EUROPE UNDER PRESSURE}

Contemporary European societies are becoming more and more diverse, and there is nothing to suggest that this tendency will be reversed. This diversity stems largely from the migratory dynamics characterising the world today. According to the International Migration Report (United Nations 2017, the number of international migrants worldwide has continued to grow rapidly over the past fifteen years, reaching 244 million in 2015. During recent decades, these fluxes of people have been particularly intense in Europe, which has witnessed new contexts and causes, one of which being conflict. According to the International Organization for Migration, 1,003,124 people were reported to have arrived in the European Union via the Mediterranean in 2015 alone; on the way, 3,771 lost their lives or were given as disappeared. From Greece, a mass of men, women and children started a journey crossing Serbia, Slovenia, Hungary and Austria, to arrive into Germany, the preferred destination. This movement became the visible side of the drama experienced by millions of people living under infrahuman conditions caused by conflict and socio-economic inequalities in countries like Syria, Iraq and Afghanistan.

Alongside this movement, the human capital flight caused by the economic crisis that affected some European countries, together with the pre-crisis arrival of many economic migrants and their departure during the crisis, introduced considerable changes in the social landscape, influencing peoples' lives, in a way or another, with greater or lesser intensity. Before the refugee movements, some European countries were already experiencing a new wave of migratory flows that have sustained economic growth and simultaneously contributed to changes in the patterns of customs, life styles, values and religions. This new European scenery has triggered ambivalent positions in the attitude domain. On the one hand, inclusiveness, motivated by egalitarian values, has become more salient, nurturing awareness of the need for equality and fairness whether in the domain of public policies (e.g. equal salaries for equal jobs; equal civil rights for everyone) or in that of interpersonal relationships (e.g. criminalisation of domestic violence and sexual harassment). The normative discourse of anti-racism and tolerance, the fight for human rights, and the demand for solidarity and collective action in defence of the neediest has become increasingly important, reaching all sectors of society and public policies. 
On the other hand, these disorganised masses of people crossing Europe have generated different kinds of fear and resistance. In 2012, the Greek authorities constructed a $12.5 \mathrm{~km}$ fence along its border with Turkey. In the summer of 2015, Hungary built a fence on its borders with Serbia and Croatia to stop migrants entering Europe from Greece. The traditional hosting countries, like Germany or France, intensified border checks to control migrant and refugee flows. These official initiatives, together with the intensification of massive deadly terrorist attacks since 2015 (e.g. Paris-Bataclan; Brussels-Airport; Nice-Bastille Day; Manchester Arena; Barcelona-Ramblas) and other episodes like the allegedly mass sexual assaults in Cologne perpetrated by Arab men during the 2015/2016 New Year's Eve celebrations, contributed to the creation of a social triad linking immigration, terrorism and Islamism in peoples' minds, boosting Islamophobia and feelings of threat associated with immigrants and refugees. Appealing to conservative values, that promote the virtues of the past and the purity of national culture, in sum, the maintenance of the status $q u o$, the extreme right wing discourse claims the need of implementing tight restrictive measures in order to protect national borders and culture from the damaging influence of immigrants.

Besides the institutional scenarios created by policy makers around the issues raised by the presence of immigrants and refugees, there is the other side of the coin - everyday life. Settlers are often distinct from the populations of receiving countries: they have a different skin colour, they speak different languages and profess different religions. Because of this, they are categorised as a specific "ethnic" or "racial" group, different from the majority. Independently of the laws regulating their integration in the hosting countries, inequalities and injustices are still part of their daily social life; and the idea that immigrants bring more trouble than benefits is shared by a significant number of the native population. The attitudes and beliefs of the hosting populations have been deeply studied from different perspectives based on data collected in representative samples: the predictors and consequences of openness/opposition to immigration (Heath et al. 2018; Ramos, Pereira and Vala 2018); the preferences in terms of integration modalities and immigrant characteristics (Bourhis et al. 1997; Guimond, Sablonnière and Nugier 2014; Heath et al. 2013; Pehrson and Green 2010); the frequency and quality of contact with immigrants (Pettigrew et al. 2011; Hewstone et al. 2014); the feelings of threat associated with their presence (Ramos, Pereira and Vala 2016; Green 2009; Schneider 2008). 
However, as far as we know, no survey based studies have made migrants the main subject of analysis and aimed at exploring their feelings, opinions and attitudes regarding the hosting countries and their migration public policies. For that reason, this study constitutes a completely new approach using survey data, namely the European Social Survey Round 7, collected in 2014/15.

We will start by discussing the role that values play in the formation of attitudes in general and attitudes towards immigration particularly. We will then present the theoretical model under analysis, which is looking at the " $\mathrm{e}$ " side of immigrants and explore their attitudes towards new immigrants. Taking into account the diversity of immigrants' profiles living in European countries, three groups are considered - nationals, immigrants from European countries, and immigrants from non-European countries. Based on the literature on the determinants of opposition to immigration, four hypotheses are contrasted: (1) former immigrants are more open to newcomers than the other two groups (the solidarity hypothesis); (2) people living under more fragile socio-economic conditions are more opposed to immigration (the self-interest hypothesis); (3) long standing immigrants develop a sense of primo-occupancy that makes them reject newcomers (the autochthony hypothesis); (4) values, as moral guiding principles, contribute over and above the other three dimensions to explain opposition/openness to immigration (the morality hypothesis).

\section{THE ROLE OF VALUES}

Values are important elements of people's lives and, for that reason, they have been at the origin of multiple reflexions, in a wide set of disciplines and from diverse perspectives. Values are meaningful objects of study for different areas of social research: whether studying the organisation of a local community, the relations between groups or the functioning of social structures, values can be considered as an important element in their understanding. The conceptualisation of values as orientations that guide, justify or clarify attitudes, norms and opinions, and consequently human action, has achieved a considerable consensus among social scientists. This perspective has oriented multiple studies on the relationship between values, attitudes and individual behaviour, and is at the origin of some value taxonomies. In this chapter, we will analyse the influence of values in opposition towards immigration using the Human Values Model of Shalom Schwartz (1992). 
From a theoretical point of view, Schwartz's model (Schwartz and Bilsky 1987 and 1990; Schwartz 1992; Schwartz et al. 2012) is framed by Rokeach's work (1973) and can also be linked to that of Inglehart (1997) and the principle of belief congruence developed by Rokeach and colleagues (1960).

The conception of the model began with Schwartz and Bilsky studies (1987 and 1990) and was based on the assumption that values represent, as conscious aims, three universal needs of human existence to which all individuals and societies have to respond: the needs of individuals as biological organisms; the requisites of coordinated social interaction; and the survival and welfare needs of groups.

These three needs can be expressed in 10 types of motivational values shared by individuals, regardless of their cultural context. They are power, achievement, hedonism, stimulation, self-direction, universalism, benevolence, tradition, conformity and security. The actions involved in achieving each one of these values have psychological and social consequences, which might be compatible or incompatible with the continuing of other types of values. For example, actions indicating obedience (conformity) will tend to conflict with those expressing autonomy (achievement), but will be compatible with actions concerning social order (security). One of the innovative aspects of Schwartz's model consists of representing values as elements of a matrix of conflicting or compatible relations. The greater the distance between two values, the greater the degree of incompatibility between their underlying motivations (Figure 5.1).

The analysis of the incompatibilities between values led the author to set them in a bi-dimensional structure made up of four types of high-order values forming two basic and bipolar conceptual dimensions: one placing selftranscendence values against those of self-enhancement; and a second, placing openness to change values against those of conservation. The first dimension reflects the conflict between acceptance of others as equals and the concern with their well-being versus the pursuit of individual success and dominion over others. The second dimension reflects the conflict between the desire for intellectual autonomy, freedom of action and orientation towards change versus obedience, the preservation of traditional practices and the protection of stability.

More recently, a refinement of the Schwartz model has partitioned the same continuum into 19 more narrowly defined values, with discernible effects 

value types and bipolar value dimensions (Schwartz, 1992)

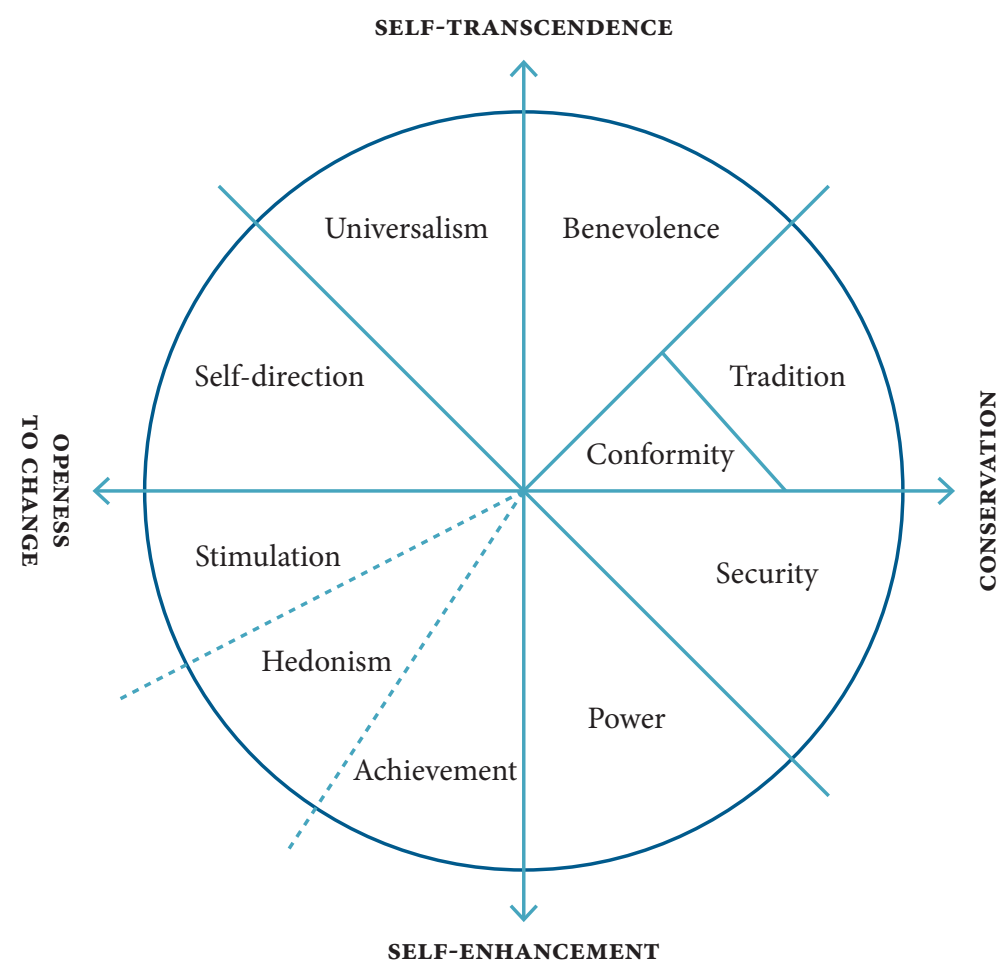

(Schwartz et al. 2012). However, for comparative reasons, the European Social Survey still uses the instrument measuring the 10 values model, the one we will be using in our analyses.

Previous studies have already shown that those endorsing the values of humanitarianism and egalitarianism share a greater concern about the most disadvantaged groups of society. They are more sensitive to the difficulties that people belonging to those groups experience, more receptive to diversity (Leong and Ward 2006) and less prejudiced towards minorities (Biernat et al. 1996). This acceptance and concern about the "Other" is specifically mirrored in the Schwartz value of universalism.

In contrast, those who hold conservative values are more likely to reject all that may jeopardise stability and control over life and over the social environment (Rockeach 1960). Coherently, these individuals are motivated by the maintenance and preservation of the status quo and by the superiority of 
their own culture, which in turn may support the relative elevation of whites, heterosexuals, males and so on, compared to other groups (Lambert and Chasteen 1997). This conservative view of society is reflected in the Schwartz conservation values.

In the context of immigration studies, Schwartz's model has been broadly tested (Davidov and Meuleman 2012; Ramos, Pereira and Vala 2016). Nonetheless, they only address the opinions of nationals (or of the total samples without distinction). The main conclusions of these studies show a general tendency for the values of self-transcendence (and specifically universalism) to generate more open attitudes towards immigrants and immigration policies, with the values of conservation acting in the opposite way, promoting higher levels of opposition to the reception of immigrants and more restrictive policies regarding immigrants' civil rights. In this regard, we cannot expect a specific association between conservation values and opposition to immigration in the case of immigrants and, for that reason, we do not put forward any correspondent hypothesis. Other studies have also shown that values are more relevant to explain attitudes towards immigration than other dimensions that are often presented as the main triggers, such as nationals' social and economic vulnerability (Ramos and Vala 2009).

Based on these empirical findings, we propose the following hypotheses ${ }^{1}$ :

H4 The higher the endorsement of universalism, the lower the opposition towards immigrants expressed by nationals and immigrants;

H5 The higher the expression of conservation values, the higher the opposition towards immigration expressed by nationals.

Most immigrants leaving their country in search of a better life are predisposed to remain in the new country for a long period (or permanently) and motivated to improve their economic situation. From this combination of characteristics, we may assume that immigrants arrive in a new country with a set of expectations that they wish to fulfil. According to Boneva and Frieze (2001), those who emigrate tend to have a stronger achievement motivation than individuals that prefer to remain in their own country. However, we

1 For theoretical reasons, the variables measuring the impact of values on opposition towards immigration will be introduced in the model after the variables measuring the solidarity and autochthony hypotheses and, for that reason, they are numbered $\mathrm{H}_{4}, \mathrm{H}_{5}$ and $\mathrm{H} 6$. 
have no empirical or theoretical arguments to preview an association between motivation for achievement and opposition to immigration in the case of immigrants.

Finally, we expect values to have an explanatory power over and above situational variables (age, education, political orientation and religiosity), self-interest indicators (subjective income, employment status and length of sojourn) (H6-morality hypothesis).

\section{THE IMMIGRANTS' PERSPECTIVE}

As mentioned above, the main objective of this chapter is to lift a corner of the veil and understand how immigrants see the entrance of other immigrants, as well as the extent to which their attitudes differ from those of nationals. Immigrants are not a homogeneous group - deriving from countries with different immigration policies and different societal contexts, they are motivated by different ambitions. Distinctive motivations can underlie their expectations: a job, a better income, career improvement, joining the family, or running from conflict and inequalities. These are undoubtedly important criteria to take into account in a sociological approach and in future studies. However, the nature of this first study is exploratory and, for that reason, comparisons between countries or between different categories of immigrants will not be addressed. Immigrants will be analysed from the point of view of what they all have in common: individuals living in a country where they were not born nor brought up and that, with the exceptions stemming from the brain drain phenomenon, often come from lower socio-economic classes, tending to occupy a low rank in the status hierarchy of the hosting society.

In theory, immigrants may share multiple identities: they are immigrants from the point of view of nationals, emigrants from their own point of view, and they can also take the place of nationals when it comes to evaluating the benefits/disadvantages of receiving new immigrants. In this chapter, we will look at immigrants through the lens of their "e" side; i.e. as emigrants, and compare their attitudes towards immigration with those of nationals. Independently of the public immigration policies, basically integrative, and regardless of the degree of identification with the majority, emigrants transform their current spaces of residence by "placing" their identities; i. e. by inserting their belonging into neighbourhoods and creating local ties (Ehrkamp 2010). By doing this, 
immigrants engage with the hosting society on their own terms and may eventually become members of the host or receiving society with respect to new settlers. The boundaries between majority and minority groups become blurred and, according to Hutnik's model (1986), immigrants may promote acculturative strategies (high identification with the ingroup and the outgroup). Moreover, belonging is not only defined by group boundaries; it can also be expressed through "claims of primo-occupancy of a territory" (Martinovic and Verkuyten 2013). The concept of autochthony is well known in anthropology, but its application to prejudice explanatory models is new. Arriving somewhere first can generate self-evident notions of ownership that may in turn be used to exclude newcomers from access to rights and power (Geschiere 2009). A similar effect was confirmed by Martinovic and Verkuyten (2013), who identified autochthony as a unique and relevant predictor of prejudice, mainly among those who fear that their entitlements are being challenged by newcomers.

These reflections lead us to propose the emergence of a double identification with different impacts on the attitudes immigrants develop towards newcomers: as emigrants, and due to their own experience, the identification with newcomers may result in more open and inclusive attitudes; as members of the community that have gained their own "place, they may share some of the nationals' concerns and manifest less open attitudes. For instance, immigrant opposition to newcomers may be driven by self-interest motivations due to a perceived unfavourable economic position or by feelings of primo-occupancy entitlements.

The data we will analyse was collected using questionnaires designed to measure the attitudes of the majority towards immigration and, therefore, we do not have attitudinal indicators specifically designed for immigrants. We know that they were not born in the country of residence and how long they have lived there. Based on the assumption that those who have been in the country for longer periods may see newcomers as a challenge, we will use sojourn as an indicator of autochthony.

Three hypotheses are drawn from these considerations: $\mathrm{H}$ - Immigrants are more open to immigration than nationals (solidarity hypothesis); H2 - Those living under more fragile social and economic circumstances are less open to immigration (self-interest hypothesis); H3 - The longer the immigrants' presence in the hosting country, the less open they are to immigration (autochthony hypothesis). These three hypotheses will be contrasted with the morality hypothesis, previously presented. 


\section{METHODOLOGY}

DATA

To analyse the impact of individual characteristics and contextual circumstances on opposition towards immigration, data from Round 7 of the ess was used (2014/15). The methodological standards followed in all participating countries guarantee a strong level of confidence in the data produced to perform comparative analysis; namely the strict probability sampling of the 15 year old or older resident population, and the rigorous translation process of the questionnaire into the several languages of the participating countries. The countries used in the analysis were the following: Austria $(1,785)$, Belgium $(1,767)$; Switzerland $(1,527)$; the Czech Republic $(2,084)$, Germany $(3,034)$; Denmark (1,492); Estonia (2,029), Spain (1,861); Finland (2,068); France $(1,903)$; the United Kingdom $(2,247)$; Hungary $(1,689)$; Ireland $(2,379)$; Lithuania (2,204), the Netherlands $(1,900)$; Norway $(1,434)$; Poland $(1,596)$; Portugal $(1,253)$; Sweden $(1,786)$ and Slovenia $(1,222)$, making a total of 37,049 respondents, 3,517 of whom being immigrants; i. e. they were not born in the country where they live (representing $9.5 \%$ of the total sample). Due to the contrast between the diversity of origins, covering the five continents, and the destination of those immigrants, which is limited to 20 European countries; two groups of immigrants were created: one from European countries and another from non-European countries. Data was weighted using the "design weight" available in the ESS data set. (For further information on the ESS methodological specifications, see www.europeansocialsurvey.org).

\section{VARIABLES}

\section{Dependent variable - Opposition towards immigration}

Four questions were used to operationalise the dependent variable: (1) “To what extent do you think [country] should allow people of the same race or ethnic group as most [country] people to come and live here?" (2) "How about people of a different race or ethnic group from most [country] people?” (3) "And how about people from the poorer countries in Europe?" (4) "How about people from the poorer countries outside Europe?"

The answers were given in a four-point scale: 1 - allow many to come and live here; 2 - allow some; 3 - allow a few; 4 - allow none. 


\section{Independent variables}

1) Situational variables

- age, gender, number of years of education, left-right orientation ("In politics, people sometimes talk of "left" and "right". Using this card, where would you place yourself on this scale, where o means the left and 10 means the right?"); religiosity ("Regardless of whether you belong to a particular religion, how religious would you say you are?" o-Not at all religious to 10-very religious)

2) Self-interest indicators

- Subjective income: "Which of the descriptions on this card comes closest to how you feel about your household's income nowadays?" (1-Living comfortably on present income; 2-Coping on present income; 3-Finding it difficult on present income; 4-Finding it very difficult on present income). This variable was recoded so that higher values represent a higher sense of comfort with the present income.

- Work situation in the last seven days: unemployed, actively looking for a job (yes/no)

3) Autochthony indicator

- Length of sojourn: "What year did you first come to live in [country]?" The indicator was transformed in order to measure the number of years living in the country.

4) Human values

The measurement of individual values was done using the Schwartz Portrait Value Questionnaire included in the Ess questionnaire. Past research showed that values we are using are equivalently measured throughout Ess countries (Davidov 2010) allowing us to use them without further tests of equivalence. Respondents were asked to answer 21 questions describing different people. In each answer, they should say how much that person resembles them (scale: 1 - very much like me to 6 - not like me at all). This procedure is current practice, but raises some problems, which must be controlled. One of these comes from the fact that individuals differ in the way they use the different points of a scale; in other words, the anchorage points. For some, everything is highly important; others, cautiously, use the medium point of the scale; others are reluctant to use extreme positions; and others even find it difficult to place themselves in the intermediate points between yes and no. It is therefore necessary to find a way of controlling this effect when we want to compare 
value priorities between countries or correlate values with other variables. The strategy that Schwartz (1992) highly advises consists in centring individual answers on the respective means, subtracting the individual mean of the 21 items from the scores given to each item. This procedure has the advantage of being usable without problems in regression analysis, namely those introduced by multicolinearity effects. In the analyses presented here, the indicators were submitted to this procedure.

The basic values of Universalism, Achievement, Tradition, Conservation and Security were used in the analyses. According to the Schwartz model, Universalism is a combination of three indicators (equality of opportunities, listening to different opinions and concern for the environment). However, we did not use the last one, since we do not have theoretical reasons to establish a link between this motivation and attitudes towards immigration. Appendix 1 summarises the operationalisation of the 10 values.

\section{RESULTS}

WHO ARE THE IMMIGRANTS CAPTURED BY THE ESS?

To better understand the findings, it is important to know the characteristics of the respondents. As explained above, two groups of immigrants were created regarding their origin: within European and outside Europe. Table 5.1 summarises the profile of each group concerning the independent variables used in the regression model.

Women are slightly more represented than men, with the exception of immigrants from outside Europe that have an almost even composition. NonEuropean immigrants are younger, more religious, express more financial difficulties and place themselves in a more left political orientation than the two other groups. Non-Europeans have completed more years of schooling than nationals and register a higher rate of unemployment, though, on average, their sojourn is shorter. Regarding this last aspect, European immigrants have been in the hosting country for longer periods than non-European immigrants.

\section{OPPOSITION TO IMMIGRATION IN EUROPE}

According to the "solidarity hypothesis" ( $\mathrm{H} 1$ ), people experiencing emigration should express a more open attitude towards immigration. As represented in 


\begin{tabular}{lccc} 
& \multicolumn{2}{c}{ IMMigRANTs } \\
& $\begin{array}{l}\text { NATIONALS } \\
(\mathrm{N}=33522)\end{array}$ & $\begin{array}{c}\text { European countries } \\
(\mathrm{N}=2259)\end{array}$ & $\begin{array}{c}\text { Non-European countries } \\
(\mathrm{N}=1258)\end{array}$ \\
\hline Gender (female) & $52.4 \%$ & $56.7 \%$ & $50.5 \%$ \\
\hline Age & 48 & 49 & 41 \\
\hline Years of school (1) & $12.9 \mathrm{a}$ & $13.1 \mathrm{ab}$ & $13.2 \mathrm{~b}$ \\
\hline Subjective income $(2)$ & $3.1 \mathrm{a}$ & $2.9 \mathrm{~b}$ & $2.8 \mathrm{c}$ \\
\hline Religiosity (3) & $4.2 \mathrm{a}$ & $4.9 \mathrm{~b}$ & $5.8 \mathrm{c}$ \\
\hline Left-right orientation $(4)$ & $5.1 \mathrm{a}$ & $4.7 \mathrm{~b}$ & $4.5 \mathrm{C}$ \\
\hline Unemployed & $4.1 \%$ & $5.4 \%$ & $10.4 \%$ \\
\hline Sojourn & nap & 28.2 years & 20.4 years \\
\hline
\end{tabular}

(1) $-F(2,37046)=9.34, p<.001 ;(2)-F(2,36684)=72.2, p<.001 ;(3)-F(2,36810)=228.2, p<.001 ;(4)-F(2,3292$ $8)=58.9, p<.001$.

Mean values with different subscripts are statistically different.

Figure 5.2, this is in fact the case. The differences between groups are statistically significant $(F(2,36447)=102.5, p<.001)$. The value of the eta ${ }^{2}$, however, reveals that the magnitude of the effect is very small $\left(\mathrm{eta}^{2}=.005\right)$, suggesting that the migration experience does not have as meaningful an impact as we would expect. Both immigrant groups' mean values of opposition to immigration are significantly different from the scale midpoint (2.5) ( $t$ European_countries (2209) $=-7.2, p<.001 ; t$ Non-European_countries $(1121)=-14.4, p<.001)$, meaning that both groups express an attitude tendentiously more open than nationals, who remain at the midpoint $\left(t_{\text {Nationals }}(33017)=1.5, n s\right)$.

Up to now, we have confirmed that nationals and immigrants have different attitudes regarding the entrance of newcomers, with nationals being less open. The next step of this study is to identify the factors associated with these different attitudes. To pursue this aim, hierarchical regression models were run for the three subsamples. Findings are presented in Table 5.1.

Looking at the first block of variables introduced in the model, three different patterns emerge. Among nationals, only gender has no impact on opposition to immigration: older people and those more identified with the right wing oppose immigration more, while the more educated and more religious tend to be more open to it. Regarding immigrants from European countries, age 
Figure 5.2 Opposition to immigration (means) 1 (allow many) to 4 (allow none)

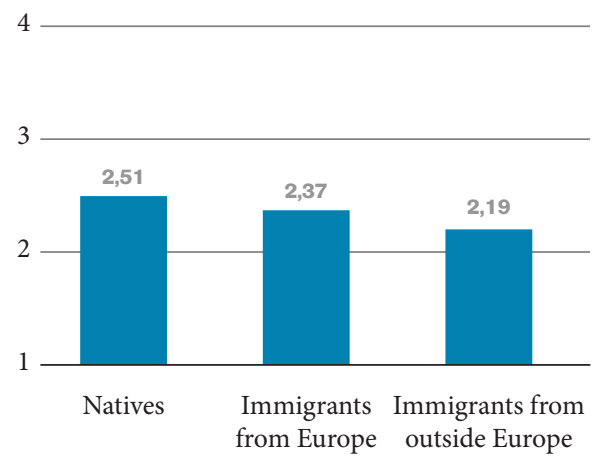

and ideological orientation have a similar impact to those observed in the nationals' sample. However, the impact of education and religiosity is not significant. This picture is even more restricted in the case of immigrants from non-European countries, among which only age has a significant impact on opposition to immigration, similar to the other two groups.

The self-interest hypothesis was built under the assumption

that those experiencing social and economic constraints are more opposed to immigration. Results show that this is not completely true: being unemployed has no effect on willingness to receive newcomers (even for immigrants outside Europe with double the unemployment percentage rate of the other two groups), and income difficulties are related to more opposition to immigration only in the subsamples of nationals and immigrants from European countries.

According to Ceuppens and Geschire (2005), autochthony implicitly calls for the exclusion of strangers, whoever they may be, and can also be used to exclude newcomers and immigrants in particular. The Ess questionnaire does not have any autochthony indicator and, for that reason, we created a variable measuring the number of years each immigrant had been living in the hosting country at the time of the questionnaire administration, using it as an indicator of autochthony. For nationals, the variable would have the same meaning as age, since they have all been in the country since they were born. Consequently, we did not include it in the nationals' model. According to our results, the autochthony hypothesis $\left(\mathrm{H}_{3}\right)$ is confirmed regarding immigrants from outside Europe. For these, the length of the sojourn may trigger a feeling of primo-occupancy that motivates a less positive attitude towards newcomers. A possible explanation for why the two groups of immigrants react differently is the fact that immigrants from outside Europe live in more adverse socio-economic conditions, probably similar to those of newcomers and, consequently, they feel they have more to lose with their presence than immigrants from inside Europe. 
Regarding the impact of values, the findings reveal remarkable differences between the three groups ${ }^{2}$. The results obtained with the group of nationals reproduce the findings of previous studies about the impact of values on attitudes towards immigration (Ramos, Pereira and Vala 2016) - and allow us to confirm $\mathrm{H}_{4}$ and $\mathrm{H}_{5}$-, with universalism and security being the values that contribute most to the explanation of openness and opposition to immigration, respectively. Adhesion to the other two higher order conservation values tradition and conformity -, as well as achievement, is also associated with higher levels of opposition, but with a less expressive contribution.

Adhesion to universalism is also the value that strongly predicts openness to immigration among immigrants. But this is the only aspect common to both groups: while the importance attributed to Conformity and Security has a significant impact on opposition to immigration in the case of immigrants from European countries; for those coming outside Europe, only Achievement is also, although modestly, associated with opposition to the entrance of newcomers. On the whole, the morality hypothesis (H6) was confirmed for the three groups, since values predict openness/opposition to immigration over and above the other two selected explanatory models, namely, self-interest and autochthony.

A final word on the validity of the tested model to explain opposition to immigration is due. For the group of nationals, the set of variables chosen contributes to explain $22 \%$ of the variance, meaning that a lot of variance in opposition to immigration remains to be explained. Regarding the two groups of immigrants, the explained variance is even lower ( $18 \%$ for European migrants and $10 \%$ for non-European migrants). This means that other models must be tested, and this is particularly the case for the non-European immigrants.

\section{CONCLUSIONS}

In order to understand the differences regarding openness/opposition to immigration expressed by nationals, immigrants from European countries and immigrants from non-European countries, four hypotheses were tested:

2 For reasons that have to do with the organisation of the chapter, the statistical tests made regarding the equivalence of value structure and salience in the three groups under analysis are presented in Annex II. 
Table 5.2 Predictors of opposition to immigration in European countries (Standardised coefficients)

\section{IMMIGRANTS}

NATIONALS

$(\mathrm{N}=33522)$
European countries Non-European countries

$$
(\mathrm{N}=2259)
$$

.010

.013

$(\mathrm{N}=1258)$

Gender

$.092^{* * *}$

Age

$-.123^{\star * *}$

Education

$-.073^{\star * *}$

$.098^{\star *}$

$-.024$

Religiosity

$.100^{* * *}$

$-.052$

$.126^{* *}$

Left-right

$-.031$

$-.035$

Adj. $R^{2}$

.091

$.122^{* * *}$

$-.019$

Subjective income

$-.157^{* * *}$

.081

.035

Unemployment

$-.010$

$-.159^{\star * *}$

.055

$R 2$ change

$.035^{* * *}$

$-.030$

$-.034$

Adj $R^{2}$

.125

$.035^{* * *}$

.005

Sejourn

$R^{2}$ change

$\operatorname{Adj} R^{2}$

Universalism

Achievement

Security

Conservation

Tradition

$R^{2}$ change

$\operatorname{Adj} R^{2}$

${ }^{* *} p<.01 ;{ }^{* * *} p<.001$.

Left-Right (o left to 10 right); Gender (Woman=1); Education (o to 30 years of schooling); Unemployment (Unemployed=1); Subjective Income (1 lower to 4 higher); Age (15 to 90). 
the solidarity hypothesis (former immigrants are more open to newcomers for empathic reasons); the self-interest hypothesis (people in more fragile socioeconomic situations oppose immigration more); the autochthony hypothesis (long standing immigrants develop a sense of primo-occupancy that makes them reject newcomers); and the morality hypothesis (as life guiding principles, values contribute over and above the other three hypotheses to explain opposition/openness to immigration).

The first important conclusion that can be drawn from this study is that immigrants are not a homogeneous group and the socio-cultural specificities that divide them need distinctive models to interpret their attitudes towards immigration. The differences found between immigrants from European and from non-European countries is an example. The impact of sojourn, for instance, is an irrelevant aspect for the former, but one of the main predictors of opposition to immigration from the latter.

Another important aspect is related to how fundamental common variables are in understanding such attitudes. For instance education has been seen as a key factor to explain attitudes and fight prejudice. However, education only appears as a significant predictor of openness for the group of nationals (and immigrants are not less educated that nationals; on the contrary). Is education, by itself, really important? Or is it the learning of normativity and correctness (social, political, moral...) that education brings that is different among the origins of the three groups? In other words, is this an effect of education, or one of social desirability? We have no data to disentangle these relationships, but this is certainly one important issue to clarify in the future.

Blaming immigrants for taking jobs from nationals is also a frequently heard claim. However, our findings show that being unemployed is not related to more restrictive preferences in any of the groups. This is particularly relevant considering that the unemployment rate of immigrants from non-European countries is twice as high as that of the other two groups.

Finally, the study confirms the role played by values in forming attitudes towards immigration. Several studies on the impact of values have reported a positive effect of universalism and a negative effect of conservation values (security, tradition and conformism) on opposition towards immigration. Universalism is the value that strongly motivates people to accept immigrants and to develop preferences for more inclusive immigration policies, and this finding was reproduced for the three groups considered in our study. Conservation values, in contrast, aim both at individual and 
social protection, as well as maintaining the status quo: goals that may be threatened by the presence of culturally diversified groups, having norms and customs that conflict with those of the native population. Our findings draw attention to the importance that these values play in the forming of nationals' and European-immigrants' attitudes to newcomers, but not for non-European immigrants. One can argue that nationals and immigrants from European countries share a cultural heritage: at an upper level they both have origins and live in Europe. Non-European immigrants may have no reason to feel the need of protecting the culture of the European country where they are living and so, although they praise tradition and conformity as much as everyone else, these values are not mobilised in forming opinions about the entrance of newcomers.

As stated at the opening of this chapter, our intention is to start filling a void in the literature on attitudes towards immigration, and look at immigrants as subjects instead of objects. Many questions have been raised, a few answered, but the floor is open for what we believe is a fertile line of research.

\footnotetext{
ALICE RAMOS

Instituto de Ciências Sociais, Universidade de Lisboa

Av. Prof. Aníbal Bettencourt 9-1600-036 Lisboa, Portugal

alice.ramos@ics.ulisboa.pt

orcid.org/oooo-0001-9512-0571
} 

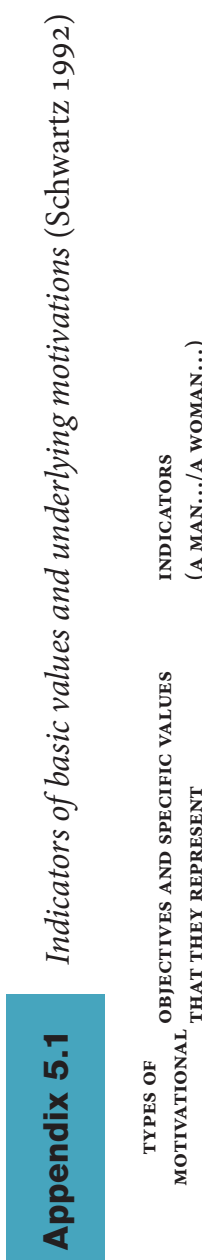

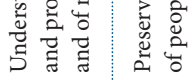
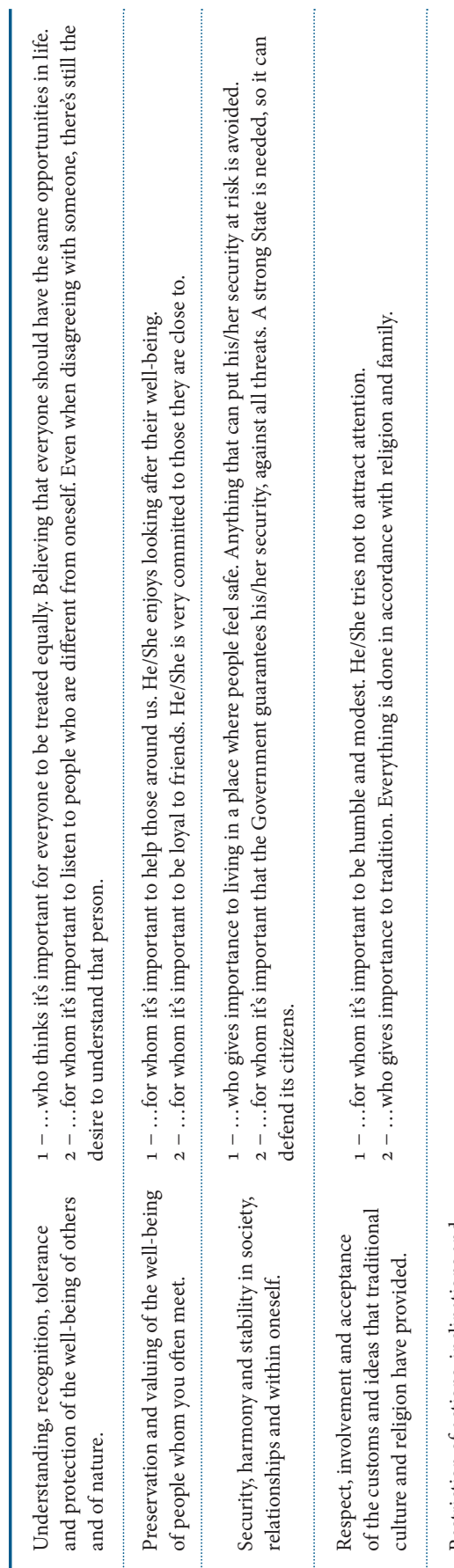

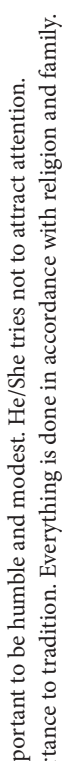

恶蹃

공

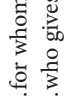

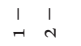

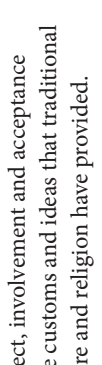

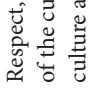

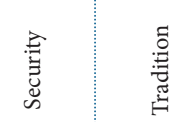

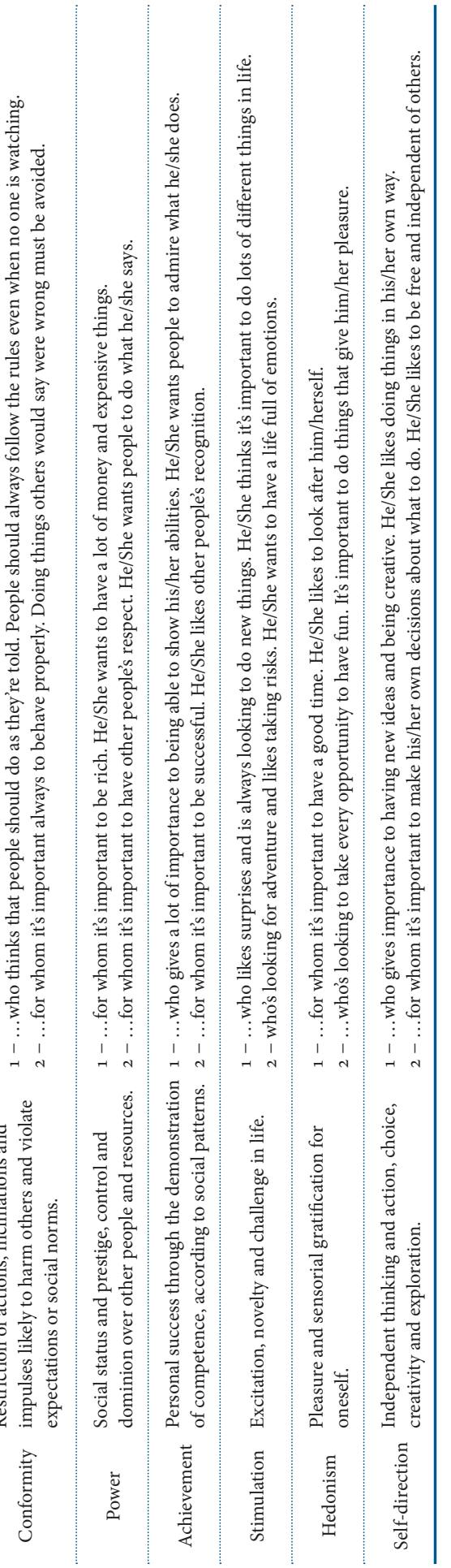




\section{Appendix 5.2}

Structure and salience of Schwartz's values - nationals, immigrants from European countries and immigrants from non-European countries

Appendix 5.2.1 - Values structure - Nationals (Multidimensional Scaling - Proxcal; Tucker coefficient of congruence $=.980$ )

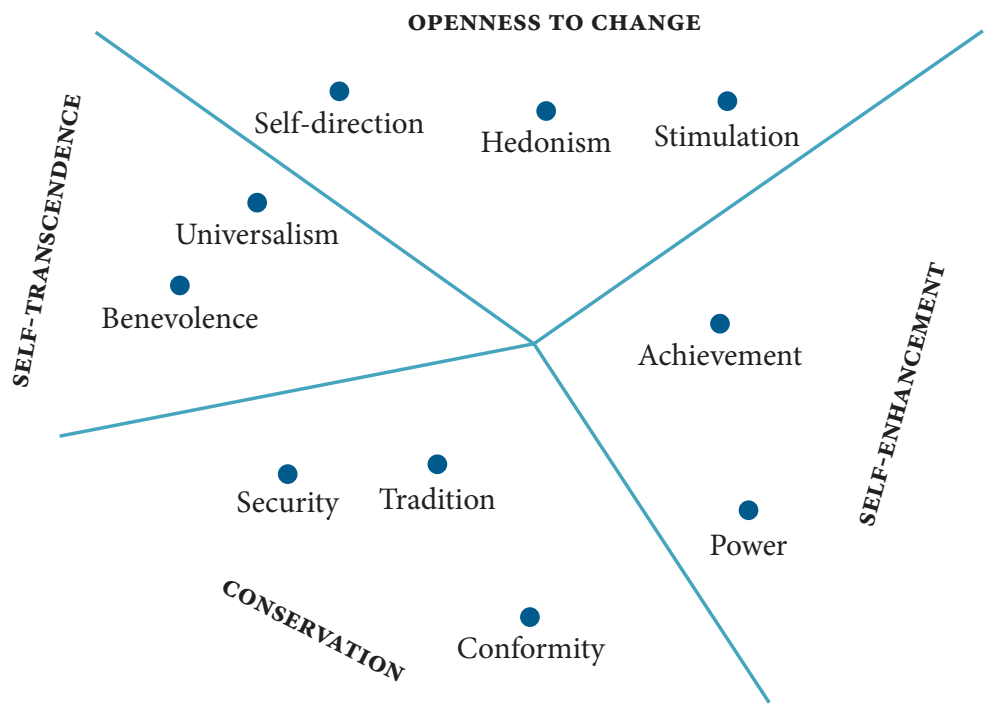

Appendix 5.2.2 - Values structure - Immigrants from European countries (Multidimensional Scaling - Proxcal; Tucker coefficient of congruence $=.981$ )

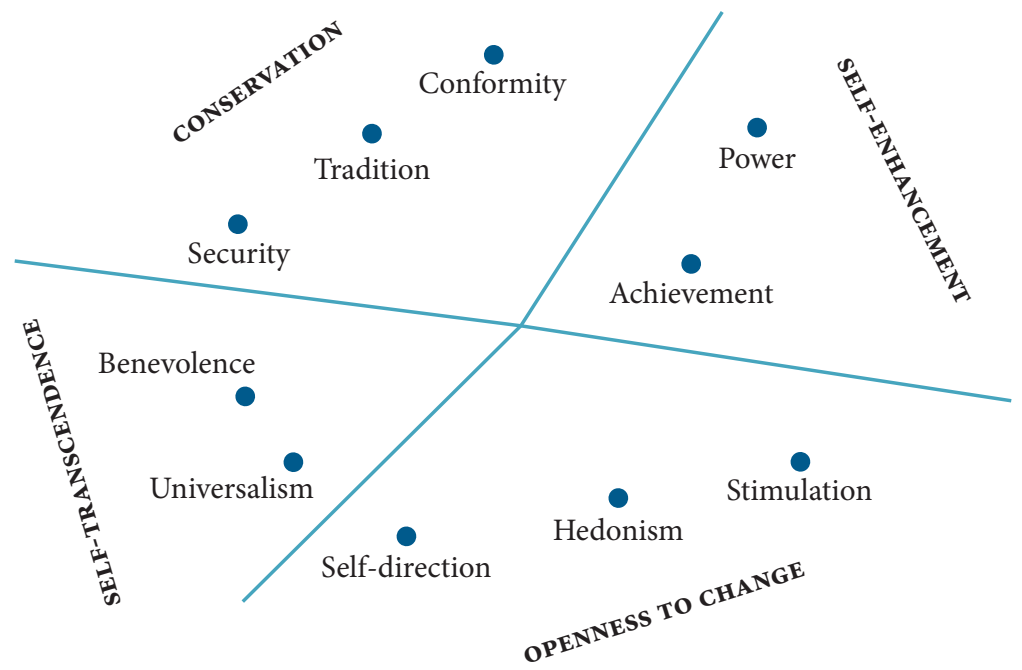


Appendix 5.2.3 - Valuesstructure-Immigrantsfromnon-European countries (Multidimensional Scaling - Proxcal; Tucker coefficient of congruence $=.978$ )

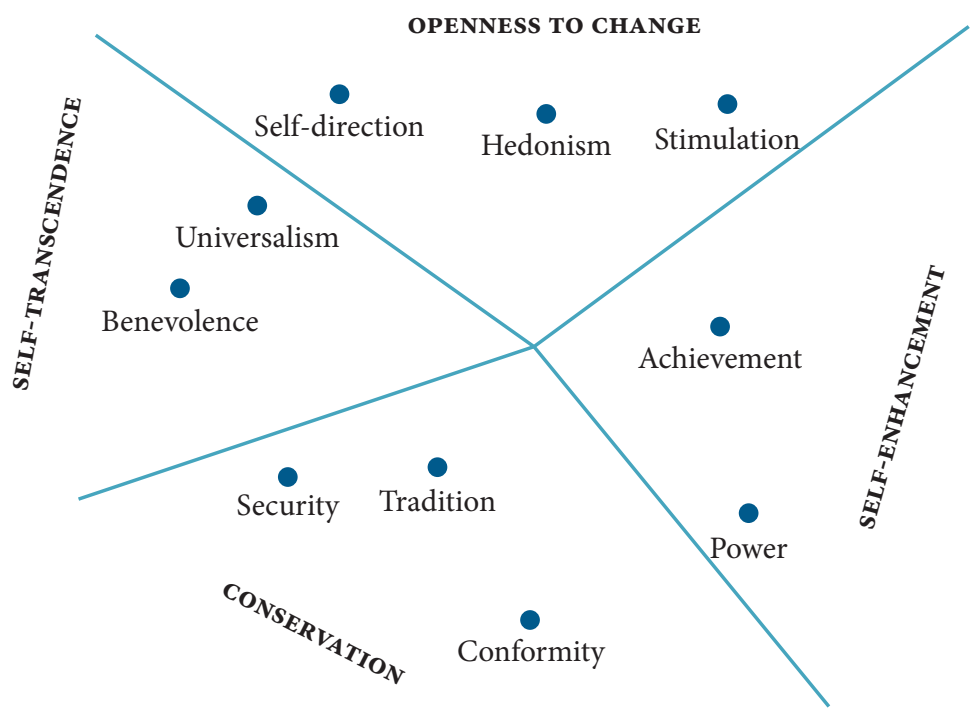

Appendix 5.2.4 - Importance attributed to the ten basic values by group (centred means)

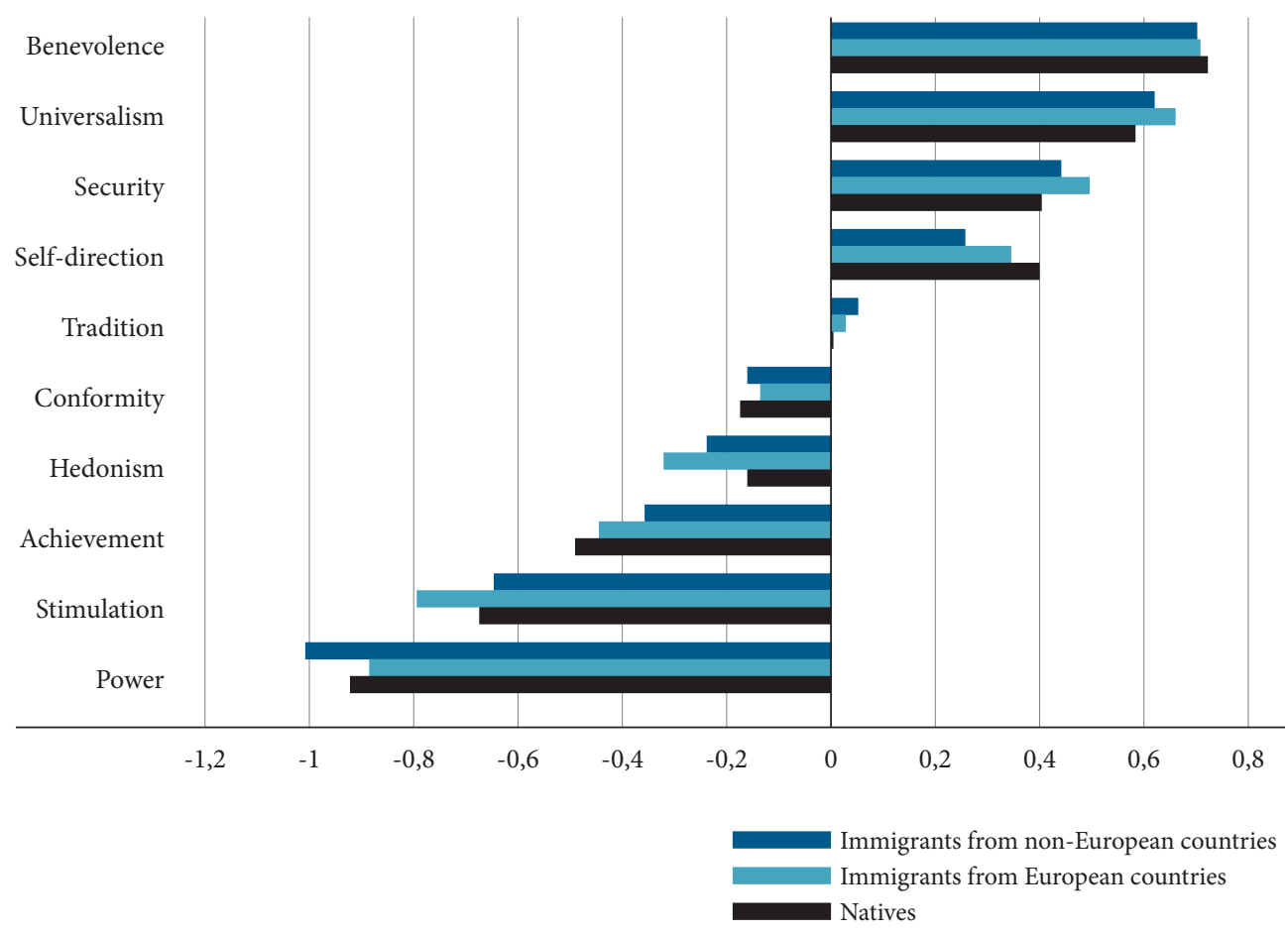




\section{$\S$ REFERENCES}

BIERnAT, M., et al. 1996. "Values and prejudice: Toward understanding the impact of American values on outgroup attitudes". In The Ontario Symposium on Personality and Social Psychology. The Psychology of Values: The Ontario Symposium, vol. 8, eds. C. Seligman, J. M. Olson and M. P. Zanna. Hillsdale, NJ, us: Lawrence Erlbaum Associates, Inc., 153-189. BONEVA, B. S., I. H. Frieze. 2001. “Toward a concept of a migrant personality”. Journal of Social Issues, 57: 477-491. DOI: 10.1111/0022-4537.00224.

BOURHIS, R. Y., et al. 1997. “Towards an interactive acculturation model: a social psychological approach". International Journal of Psychology, 32:369-386. DoI:10.1080/002075997400629.

Ceuppens, B., P. Geschiere. 2005. "Autochthony: local or global? New modes in the struggle over citizenship and belonging in Africa and Europe". Annual Review of Anthropology, 34 (1): 385-407.

DAVIDOV, E. 2010. "Testing for comparability of human values across countries and time with the third round of the European Social Survey". International Journal of Comparative Sociology, 51 (3): 171-191.

DAvidov, E., B. Meuleman. 2012. "Explaining attitudes towards immigration policies in European countries: the role of human values". Journal of Ethnic and Migration Studies, 38 (5): 757-775.

Geschiere, P. 2009. "The Perils of Belonging". Autochthony, Citizenship and Exclusion in Africa and Europe. Chicago \& London: The University Press of Chicago.

GREEN, E. G. T. 2009. "Who can enter? A multilevel analysis on public support for immigration criteria across 20 European countries". Group Processes and Intergroup Relations (12): 41-60.

Guimond, S., R. de la Sablonnière and A. Nugier. 2014. "Living in a multicultural world: intergroup ideologies and the societal context of intergroup relations". European Review of Social Psychology, 25 (1): 142-188. DOI: 10.1080/10463283.2014.957578.

HeAth, A. et al. 2013. The Political Integration of Ethnic Minorities in Britain. Oxford: Oxford University Press.

HEATH, A. et al. 2018. "Explaining attitudes toward immigration: Findings from the immigration module in the European Social Survey 2014-15." Journal of Ethnic and Migration Studies.

HUTNIK, N. 1986. "Patterns of ethnic minority identification and modes of social adaptation". Ethnic and Racial Studies, 9 (2): 150-167. DoI: 10.1080/01419870.1986.9993520.

Inglehart, R. 1997. Modernization and Post-modernization: Cultural, Economic, and Political Change in 43 Societies. Princeton: Princeton University Press.

LAMbert, A. J., A. L. Chasteen. 1997. "Perceptions of disadvantage versus conventionality: political values and attitudes toward the elderly versus blacks". Personality and Social Psychology Bulletin, 23 (5): 469-481. DoI: 10.1177/0146167297235003.

LEONG, C.-H., C. Ward. 2006. "Cultural values and attitudes toward immigrants and multiculturalism: the case of the Eurobarometer survey on racism and xenophobia”. International Journal of Intercultural Relations, 30: 799-810. DoI: 10.1016/j.ijintrel.2006.0 7.001.

Hewstone, M., et al. 2014. "Intergroup contact and intergroup conflict". Peace and Conflict: Journal of Peace Psychology, 20 (1): 39-53.

MARTINOvic, B., M. Verkuyten. 2013. "'We were here first, so we determine the rules of the game': Autochthony and prejudice towards out-groups". Eur. J. Soc. Psychol., 43: 637-647. DOI: $10.1002 /$ ejsp.1980. 
EHRKAMP. P. 2010. "Placing identities: transnational practices and local attachments of Turkish immigrants in Germany". Journal of Ethnic and Migration Studies, 31 (2), 345-364. DOI: $10.1080 / 1369183042000339963$.

PEHrson, S., E. G.T. Green. 2010. "Who we are and who can join us: National Identity content and entry criteria for new immigrants". Journal of Social Issues, 66 (4): 695-716. DOI: 10.11 11/j.1540-4560.2010.01671.x.

RAmOS, A., J. Vala. 2009. "Predicting opposition towards Immigration: economic resources, social resources and moral principles”. In Quod Erat Demonstrandum: From Herodotus' Ethnographic Journeys to Cross-Cultural Research, eds. A. Gari and K. Mylonas. Athens: Pedio Books Publishing, 245-254.

RAmos, A., C. Pereira, and J. Vala. 2016. "Economic crisis, human values and attitudes towards immigrants". In Values, Economic Crisis and Democracy, orgs. M. Voicu, I. Mochmann and H. Duelmer. London and New York: Routledge, 104-136.

RAmos, A., C. Pereira, and J. Vala. 2018. "The impact of biological and cultural racisms on attitudes towards immigrants and immigration public policies". Journal of Ethnic and Migration Studies.

rokeACH, M. 1960. The Open and Closed Mind. New York: Basic Books.

ROKeach, M. 1973. The Nature of Human Values. New York: Free Press.

SCHNEIDER, S. L. 2008. "Anti-immigrant attitudes in Europe: outgroup size and perceived ethnic threat”. European Sociological Review, 24 (1): 53-67. Dor: https://doi.org/10.1093/ esr/jcmo34.

SCHWARTZ, S. H. 1992. "Universals in the content and structure of values: theoretical advanced and empirical testes in 20 countries". In Advances in Experimental Social Psychology, org. M. Zanna. New York: Academic Press, 1-65.

SCHWARTZ, S. H., W. Bilsky. 1987. “Toward a universal psychological structure of human values". Journal of Personality and Social Psychology, 53 (3): 550-562.

SCHWARTZ, S. H., W. Bilsky. 1990. "Toward a theory of the universal content and structure of values: Extensions and cross-cultural replications". Journal of Personality and Social Psychology, 58 (5): 765-778.

SCHWARTZ, S. H. et al. 2012. "Refining the theory of basic individual values". Journal of Personality and Social Psychology, 103 (4): 663-688.

PETTIGREW, T. F. et al. 2011. "Recent advances in intergroup contact theory". International Journal of Intercultural Relations, 35 (3): 271-280. DoI:10.1016/j.ijintrel.2011.03.001.

United nations, Department of Economic and Social Affairs, Population Division. 2017. International Migration Report 2017: Highlights (sT/ESA/SER.A/404).

CITE THIS CHAPTER AS:

RAMOS, A. 2018. "Immigration through the lens of nationals and immigrants: self-interest, solidarity, autochthony and moral determinants". In Changing Societies: Legacies and Challenges. Vol. I. Ambiguous Inclusions: Inside Out, Inside In, eds. S. Aboim, P. Granjo, A. Ramos. Lisbon: Imprensa de Ciências Sociais, 113-135.

https://doi.org/10.31447/ics9789726715030.05 